\title{
Uso de fontes de informação por gestores de startups
}

\author{
Flavia de Souza Magalhães Fonseca ${ }^{I}$ \\ Ricardo Rodrigues Barbosa ${ }^{I I}$ \\ Frederico Cesar Mafra Pereira ${ }^{I I I}$
}

\begin{abstract}
IUniversidade Federal de Minas Gerais, Belo Horizonte, MG, Brasil.
Doutoranda e mestre em Ciência da Informação.

${ }^{I I}$ Docente da Escola de Ciência da Informação - ECI/UFMG.

${ }^{I I I}$ Fundação Pedro Leopoldo, Pedro Leopoldo, MG, Brasil.

Docente na Centro Universitário UNA.
\end{abstract}

http://dx.doi.org/10.1590/1981-5344/3492

A pesquisa focalizou o uso de fontes de informação sobre o ambiente organizacional por gestores de startups. Buscou-se caracterizar a relevância dos setores do ambiente externo para o negócio, os fatores que motivam a busca de informação por parte do gestor, e o grau de relevância e confiabilidade das fontes de informação. A metodologia de pesquisa foi baseada na combinação de métodos quantitativos e qualitativos. Para a coleta de dados quantitativos, foi utilizado um questionário online, por meio do qual foram obtidas 60 respostas. Após a análise de resultados, como método de pesquisa qualitativo, foram realizadas entrevistas com três gestores envolvidos com programas de incubação, aceleração e investimento em startups, para que os dados fossem discutidos. Os resultados demonstraram que os empreendedores reconhecem os clientes e a tecnologia como principais setores do ambiente externo que afetam seus negócios, e que há preocupação em buscar informações para gerar inovações e embasar decisões. Além disso, foi possível verificar a relevância e a confiabilidade atribuídas às fontes de informação internas, como sócios/empregados e bases de dados de suas próprias empresas, e a relevância de novas fontes digitais de informação, em detrimento de fontes tradicionais. 
Palavras-Chave: Fontes de Informação; Uso de Informação; Gestão da Informação; Empreendedorismo; Startups.

\section{Use of information sources by managers of startup companies}

The study focused the use of information sources about the organizational environment by startup managers. The research characterized the relevance of the external environment sectors for business, the factors that motivate the managers to seek information, and the relevance and reliability of information sources. The research methodology was based on the combination of quantitative and qualitative methods. The collection of quantitative data, was made through the use of an online questionnaire through which 60 responses were obtained. After the analysis of the quantitative interviews were conducted with three managers involved in the incubation, acceleration and startup investment programs, in order to discuss the data. Research has shown that entrepreneurs recognize customers and technology as key external environment sectors that affect their businesses and demonstrated their concern to seek information in order to generate innovation and support decisions. In addition, the study showed the relevance and reliability attributed to internal information sources, such as partners/employees and their own corporate databases; and the relevance of new digital information sources as compared with traditional sources.

Keywords: Information Sources; Information Use; Business Management; Entrepreneurship; Startups.

Recebido em 27.03.2018 Aceito em 04.02.2019

\section{Introdução}

O volume de dados disponíveis em todas as esferas da vida e das mais diversas naturezas e fontes - nos planos pessoal e profissional imprime novos paradigmas e torna mais complexas as relações na chamada sociedade da informação ou do conhecimento, caracterizada pela era pós-industrial ou pós-capitalista (DRUCKER, 1999).

Se, do ponto de vista pessoal, é grande o desafio de conviver com a crescente avalanche de dados produzidos diariamente, no ambiente 
organizacional a complexidade é ainda maior. Nesse contexto, o fluxo informacional que permeia 0 dia a dia das empresas exige dos profissionais maior agilidade, assertividade para acessar e interpretar dados, gerar informações, compartilhar conhecimento e tomar decisões. Nesse sentido, diversos autores destacam a relevância da informação e do conhecimento na esfera organizacional. Conforme Davenport e Prusak (1998), numa economia global, o conhecimento pode ser a maior vantagem competitiva de uma empresa. Para Stewart (1998, p.13), "a informação e o conhecimento são as armas termonucleares competitivas de nossa era". E Nonaka; Takeuchi (2008, p.39) afirmam que "em uma economia onde a única certeza é a incerteza, a fonte certa de vantagem competitiva duradoura é o conhecimento".

Segundo Choo (2003), em contextos organizacionais, podem ser consideradas três arenas onde a criação e o uso da informação exercem papel estratégico no desempenho e capacidade de adaptação: 1) a organização usa a informação para dar sentido às mudanças do ambiente externo; 2) a organização cria, organiza e processa a informação de modo a gerar novos conhecimentos por meio do aprendizado; 3) a organização busca e avalia informações de modo a tomar decisões.

Apropriar-se de informações, saber acessá-las e usá-las, bem como garantir a retenção e disseminação do conhecimento dentro das empresas, de forma ágil e estratégica, não é um desafio simples. Para Davenport; Prusak (1998), as organizações são constituídas de pessoas cujos valores e crenças, inevitavelmente, influenciam seus pensamentos e atos. Conforme Choo (2003), a informação e o insight nascem no coração e na mente dos indivíduos, e a busca e o uso da informação são um processo dinâmico e socialmente desordenado que se desdobra em camadas de contingências cognitivas, emocionais e situacionais. Para destacar outro aspecto subjetivo, quanto ao de uso da informação, Wilson (1997) afirma que nem sempre a informação acessada é processada ou usada. Ou seja, em ambientes organizacionais, os processos informacionais são pouco claros e mal delimitados; são complexos e envolvem muitos aspectos subjetivos.

No sentido de contribuir para ampliar o campo de estudos de fontes de informação e sua aplicação em ambientes de empreendedorismo, objetivou-se com esta pesquisa identificar quais são as fontes de informação utilizadas por gestores de startups do Estado de Minas Gerais. Como objetivos específicos, a pesquisa procurou caracterizar: a relevância dos setores do ambiente externo para o negócio; fatores que motivam a busca de informação por parte do empreendedor; grau de relevância das fontes de informação; grau de confiabilidade das fontes de informação; e compartilhamento de informações dentro da empresa. A coleta de dados quantitativos foi realizada no período de 16/11/2016 a 24/01/2017.

O termo startup utilizado nesta pesquisa refere-se a pequenas empresas nascentes, caracterizadas por modelos de negócios inovadores e com alto potencial de escalabilidade, porém, altamente suscetíveis a riscos. Na definição de Ries (2011), uma startup é uma instituição 
humana constituída para criar novos produtos ou serviços sob condições de extrema incerteza.

Minas Gerais foi o estado escolhido como base de pesquisa por reunir a segunda maior comunidade de startups do Brasil, de acordo com a Associação Brasileira de Startups - ABStartups. A instituição possui cadastro de 4.203 startups (www.abstartups.com.br Acesso em: 13/02/2017), sendo a maior parte delas concentrada em São Paulo (1.308), Minas Gerais (363), Rio de Janeiro (341), Rio Grande do Sul (213), Paraná (193), Santa Catarina (185), Pernambuco (114), Distrito Federal (83), Goiás (80), Ceará (68) e Bahia (67).

\section{Informação em ambientes organizacionais}

A grande disponibilidade de dados, informação e conhecimento nos ambientes interno e externo das organizações representa um relevante recurso que permite às empresas se prepararem para enfrentar os desafios de forma mais estruturada, podendo se tornar mais competitivas.

O estudo do conhecimento organizacional, no que se refere ao acesso a dados e informações de forma assertiva, rápida e orientada às estratégias, faz-se necessário numa época em que "empresas, governos e universidades têm à disposição uma montanha de informações sobre quase tudo, e ela é maior do que nunca. A questão agora é ter acesso ao que se quer, é ter informação sobre a informação." (BURKE, 2012, p.175).

Burke (2012, p. 184) ainda cita a "síndrome da agulha no palheiro ou, em linguagem mais atual, o problema de distinguir entre o que se quer ouvir e o 'ruído' de interferência." De fato, o excesso de dados pode dificultar a identificação e a extração de significado de dados que realmente importam, tal como afirmam Davenport; Prusak (1998). Esses autores apontam, ainda, a dificuldade para se determinar o caminho que vai do conhecimento até a ação, uma vez que o conhecimento e as decisões estão, de modo geral, na cabeça das pessoas.

A tecnologia também é um elemento-chave nos processos informacionais, sendo tema recorrente na Ciência da Informação (TARAPANOFF, 2006). Se a tecnologia pode ajudar na construção do conhecimento, por outro lado, ela também pode representar a vilã nesse processo. Tal como afirma Burke (2012, p.183), "a tecnologia tem sido empregada não só para colher, mas também para ocultar a informação."

Nos atuais ambientes de negócios, para que uma empresa consiga desenvolver-se de forma competitiva, é preciso que ela monitore e gerencie informações dos ambientes interno e externo. De acordo com Rodrigues; Blattmann (2014, p.9), "para que a gestão da informação seja realizada de forma adequada, é importante conhecer as fontes de informação, tanto internas quanto externas." Segundo estes autores, as fontes possuem diferentes formatos, natureza e conteúdos. A relevância das fontes de informação para a competitividade também é citada por Gomes; Kruglianskas; Scherer (2011), que as relacionam aos processos 
de gestão da inovação, desafio crucial para as organizações de todos os portes.

Conforme Choo (2003), as necessidades de informação variam de acordo com a profissão ou o grupo social do usuário, suas origens demográficas e os requisitos específicos da sua tarefa; ele afirma que os usuários obtêm informações de muitas e diferentes fontes, formais e informais, sendo que as fontes informais (colegas, contatos pessoais) são quase sempre tão ou mais importantes que as fontes formais (bibliotecas, bancos de dados). A relevância das fontes de informação interpessoais também foi destacada por Davenport; Prusak (1998), cujos estudos demonstram que gerentes adquirem dois terços de sua informação e conhecimento em reuniões face a face ou em conversas telefônicas. Apenas um terço provém de documentos. Além do mais, de acordo com Choo (2003), um grande número de critérios pode influenciar a seleção e o uso das fontes de informação; além disso, alguns grupos de usuários preferem fontes locais e acessíveis, em detrimento da qualidade de outras fontes menos próximas.

Com o advento das novas tecnologias de Internet, Alvarenga (2003) cita a questão da desterritorialização de documentos - um múltiplo universo de fontes de informação disponíveis, confiáveis e não-confiáveis, que desafia, cotidianamente, os indivíduos nas organizações. Para a autora, o meio digital se constitui em espaço sem precedentes para a representação, registro e recuperação de documentos textuais, sonoros e iconográficos. Tarapanoff (2006) também faz menção à internet, caracterizando-a como um canal de transmissão de informações formais e informais. Para a autora, as informações formais possuem maior consistência, podendo ser validadas; as informais ou de caráter temporário, de importância primordial para a inteligência competitiva, não podem ser obtidas por consulta de bases de dados.

Diversos autores desenvolveram modelos de classificação de fontes de informação utilizadas em contextos organizacionais. Conforme Brum; Barbosa (2009), a internet, como fonte de informação, pode ser dividida em vários setores: listas de discussão, correio eletrônico (e-mail), informativos via correio eletrônico (newsletter), informativos comerciais via correio eletrônico (e-mail marketing), salas de bate-papo virtual (chat), mensageiros eletrônicos (instant messengers), sites de busca ou ferramentas de busca, intranets, extranets e os próprios sites disponíveis na $w e b$. Segundo os autores, a internet ocupa um espaço importante nos processos informacionais e no comportamento de usuários em termos de necessidade, busca e uso de informação.

Atualmente, as redes sociais se configuraram como importantes fontes de informação na internet, constituindo-se também como importantes canais de comunicação para as organizações. Partindo da consideração de Ritzmann (2012), as redes sociais online são ferramentas, plataformas digitais ou softwares sociais presentes na internet que mediam as relações sociais entre atores e permitem o estabelecimento de conexões e troca de informações na rede. De acordo 
com Anastácio; Vieira (2013), com o advento da sociedade da informação, as novas práticas informacionais de busca e recuperação marcam um novo modelo na geração de conhecimento, que interfere nos mecanismos de buscas e divulgação da produção intelectual, principalmente na plataforma web. Perin (2015) lista algumas redes sociais usadas pelas startups, pelo seu poder de disseminação e relacionamento: Facebook, Instagram, LinkedIn, Twitter, YouTube e Slide Share. Segundo o autor, as redes sociais são as vozes e os ouvidos mais rápidos que uma startup pode ter.

Pereira; Barbosa (2008) propuseram um modelo de classificação das fontes de informação usadas por consultores empresariais, que considera: origem (fontes internas ou externas); relacionamento ou proximidade (fontes pessoais ou impessoais); e mídia (fontes eletrônicas e nãoeletrônicas). Já Pizzol; Todesco; Todesco (2016) utilizaram um modelo de caracterização da informação que considera o conceito de origem primária (informação gerada pelo próprio concorrente, como relatórios anuais, discursos e entrevistas) e secundária (informação gerada em outras fontes que observam os concorrentes, como jornais, revistas e relatórios de analistas); domínio público (informações tornadas públicas pelos concorrentes, como balanço de S.A. e publicações na web) e não-público (informações que não são publicadas pelos concorrentes, como pesquisas em feiras e com forças de vendas); e quanto ao tipo hard (informações baseadas em dados quantitativos, como relatórios estatísticos e financeiros) e soft (informações baseadas em dados qualitativos, como entrevistas, discursos, boatos e rumores).

As fontes de informação digitais vêm ganhando cada vez maior relevância no contexto das organizações em geral e no universo de startups. Entretanto, notou-se a falta de uma tipologia atualizada que fizesse sentido para esta pesquisa, focada em um ambiente organizacional pouco mencionado no campo da Ciência da Informação. Assim, foram feitos adaptações e acréscimos de fontes pela autora. Algumas fontes foram excluídas, por não pertencerem ao universo dos gestores de startups e outras fontes foram agrupadas em um só item. Além disso, foram acrescentadas novas fontes, por serem mais recentes do mundo digital. Essas adequações se fizeram necessárias uma vez que as startups são modelos de empresas relativamente recentes, com especificidades organizacionais que precisam ser consideradas nos estudos do campo e de empreendedorismo, cujo contexto é detalhado a seguir.

\section{Empresas startups}

Em todo o mundo, as atividades empreendedoras destacam-se como alavancas do desenvolvimento social e econômico, sendo associadas principalmente à geração de emprego e renda, conforme aponta o GEM (2014). É no mundo denominado por Perin (2015) como do "empreendedorismo de alto impacto" que surgem as startups. As primeiras startups surgiram no Brasil no começo do século XXI, sendo 
que, a partir de 2010, essas empresas cresceram vertiginosamente, de acordo com a ABStartups. Segundo a instituição, essas empresas têm modelos de negócios, em sua maioria Business to Business - B2B. A maior parte está cadastrada no mercado de Software as a Service SaaS/Web Aplicativo - App. O Brasil é o país que mais se destaca em termos de capacidade empreendedora, segundo pesquisa do GEM (2015), quando são analisados os principais fatores que favorecem a abertura e manutenção de novos negócios. Em relação aos principais obstáculos, o estudo aponta como entraves as políticas governamentais, educação e capacitação, sendo esses dois últimos os de maior atenção destacados por especialistas.

O desenvolvimento de um ambiente empreendedor e propício à inovação numa determinada região ocorre a partir de uma ação coordenada, segundo Malczewski (2015).

Tem que haver uma universidade para criar massa crítica, empresas de grande porte que demandam produtos ou componentes de tecnologia e algum tipo de fomento, como uma incubadora e linhas de financiamento. (MALCZEWSKI, 2015, p.174).

Um estudo da Associação Catarinense de Empresas de Tecnologia (ACATE, 2016) sobre o Panorama de Inovação e Tecnologia, em 2015, coloca Minas Gerais em segundo lugar no ranking de densidade de empreendedores no Brasil, com 145 a cada 100 mil habitantes, ficando atrás apenas do Distrito Federal, que registra 319. Como exemplo, em Belo Horizonte, destaca-se uma comunidade de startups autonomeada San Pedro Valley, numa referência ao bairro São Pedro, na capital mineira (onde se localizaram inicialmente), e ao Vale do Silício americano.

O sucesso do Vale do Silício inspira empreendedores e o entendimento do seu modelo serve como referência para ações de desenvolvimento econômico. Além do Vale do Silício, há outros clusters de reconhecimento mundial, como o ecossistema de startups de Israel, país que se destaca pelo grande número de cientistas, incentivo do Governo ao empreendedorismo e atração de multinacionais, bem como excelência acadêmica, potencializada por incubadoras de empresas.

Também são considerados melhores ecossistemas de startups do mundo, conforme Perin (2015): Las Vegas, onde existe a comunidade de empreendedores que se chama Downtown Project e que promove diversos eventos e interações entre investidores e mentores; Vancouver, no Canadá, onde o governo investe na interação com startups e promove o fomento a novos negócios nas universidades; Singapura e Malásia, por desenvolverem programas de atração de talentos e internacionalização de startups; e Chile, país que desenvolveu, com a intenção de diversificar a economia e promover o empreendedorismo, o programa Startup Chile, famoso por atrair startups mundiais com subsídios do governo.

No Brasil, empreendedores são motivados por todas essas experiências de sucesso. Existem comunidades de startups reconhecidas em Recife, Santa Catarina, São Paulo e Rio de Janeiro, nas capitais e no interior. De acordo com Perin (2015), essas cidades destacam-se em 
função da iniciativa de empreendedores isolados, governo, universidade e setor privado, ou pela combinação desses fatores de investimento, como é o caso de Minas Gerais, com o programa de governo estadual Startups and Entrepreneurship Ecosystem Development - Seed, criado em 2013 e inspirado no programa Startup Chile.

Embora o San Pedro Valley seja o mais conhecido cluster de startups de Belo Horizonte, outras empresas estão distribuídas na capital mineira e no interior do Estado, seja em parques tecnológicos, incubadoras de empresas ou aceleradoras. Para citar alguns exemplos: o projeto BioStartup Lab, da Biominas, a Fumsoft e o Parque Tecnológico de Belo Horizonte - $\mathrm{BH}-\mathrm{TEC}$, na capital mineira; o Centro Tecnológico de Desenvolvimento Regional de Viçosa - Centev; o polo de TI de Santa Rita do Sapucaí, com destaque para as ações do Instituto Nacional de Telecomunicações - Inatel; as empresas nascentes vinculadas às universidades de Uberlândia e Montes Claros, além de outras. Esta pesquisa de mestrado procurou atingir todas essas empresas, tal como descrito na metodologia.

\section{Procedimentos metodológicos}

A presente pesquisa é ancorada na combinação das metodologias quantitativa e qualitativa. Seguindo o princípio de Donmoyer (2008), que conceitua a investigação por métodos mistos como a integração sistemática de métodos qualitativos e quantitativos num único estudo, o objetivo de combinar esses métodos é obter uma visão mais abrangente e uma compreensão mais profunda do fenômeno pesquisado. A combinação de métodos, na visão de Ritchie (2003), mesmo reconhecendo as diferenças de suas bases ontológicas e epistemológicas, faz sentido se isso trouxer algum novo insight para o estudo.

Para a pesquisa quantitativa, considerou-se a afirmativa de Kothari (2004), segundo a qual a estatística na atualidade tem contribuído de forma significativa para a tomada de decisão, e a orientação de Hank; Jordan; Wildemuth (2009), que sugerem perguntas introdutórias para o questionário, seguidas das questões-chave e, por último, dados do entrevistado. A etapa quantitativa da pesquisa contemplou a coleta de dados sobre o cenário mundial, brasileiro e mineiro de startups, via emails de empreendedores de Minas Gerais. Foram consultados os sites da ABStartups (363 empresas), San Pedro Valley (cerca de 200 empresas), de seis parques tecnológicos, incubadoras e aceleradoras (23) e universidades de Minas Gerais, além de clusters produtivos e associações de classe (como de Tecnologia da Informação e Biotecnologia), hubs (espaços de coworking) e empresas de investimento, que reúnem 0 cadastro dos empreendedores de startups do Estado.

A partir de cerca de 800 contatos iniciais, a lista foi filtrada, com o objetivo de reduzi-la a profissionais e gestores associados exclusivamente a startups. Após esta seleção, chegou-se ao número de 495 e-mails de gestores de startups. 
Na etapa de pré-teste, foi elaborado e aplicado um questionário a quatro empreendedores escolhidos através de amostra não-probabilística por julgamento. Estes gestores representaram: uma startup de biotecnologia (empreendedor 1), uma startup de serviços de computação em nuvem (empreendedor 2), uma startup de serviços mobile para motociclistas (empreendedor 3) e uma aceleradora de startups privada (empreendedor 4). Nesta etapa de pré-teste, também foram definidas, com a colaboração dos participantes, as 30 fontes de informação utilizadas na pesquisa.

Foram consideradas, como referência para elaboração do instrumento definitivo de coleta de dados, as fontes de informação baseadas nos modelos de Pereira; Barbosa (2008) e Pizzol; Todesco; Todesco (2016), bem como nos critérios destacados por Pereira; Barbosa (2008), com adaptações e acréscimos de fontes digitais.

A coleta de dados quantitativos teve a duração de dois meses período em que o questionário foi disponibilizado via Google Forms. O link da pesquisa foi divulgado entre empreendedores por meio de e-mail. Para reforçar a divulgação, foi solicitado apoio às instituições de incubação, aceleração, hubs, parques tecnológicos e empresas investidoras. Também foram usados como canais de divulgação cinco grupos de discussão no Facebook, feed de atualização do LinkedIn e um grupo de WhatsApp de empreendedores de startups de Minas Gerais. Como resultado final, foram obtidas 60 respostas à pesquisa.

Para se chegar a esta amostra, foram feitos três disparos de e-mails para a base de empreendedores, sendo que, no primeiro disparo, do total de contatos, 89 foram caracterizados como soft e hard bounces (e-mails que não foram entregues e inexistentes) e três pessoas pediram sua exclusão da lista. Assim, o universo pesquisado se restringiu a 403 contatos válidos. As instituições foram acionadas por e-mail e telefone, para ressaltar a importância da pesquisa; e o trabalho nas redes sociais teve como objetivo esgotar as possibilidades de contato com os empreendedores. A pesquisa englobou um universo populacional delimitado, cuja abordagem foi feita à exaustão; o número de respondentes foi de quase $15 \%$ (14,8\%). De acordo com Mattar (1996), quando há saturação de amostra em população finita, o número máximo alcançado de respostas permite inferir sobre o universo. Esta amostra, usando ferramentas de cálculo amostral para pesquisas quantitativas, tem nível de confiança de $90 \%$ e margem de erro de $10 \%$.

Os dados qualitativos desta pesquisa foram coletados por meio de entrevistas individuais com três profissionais gestores de: parque tecnológico (Gestor 1), empresa de investimentos (Gestor 2) e programa público de aceleração de startups (Gestor 3). Esses participantes da pesquisa foram escolhidos através de amostra não-probabilística por julgamento, considerando que, por lidarem com grandes grupos de empreendedores de startups, poderiam agregar subsídios à análise. Esta etapa consistiu na apresentação online dos resultados obtidos a partir do 
questionário quantitativo e na discussão dos dados, por meio de roteiro semiestruturado.

\section{Apresentação e análise dos resultados}

Serão apresentados neste tópico, os resultados da pesquisa, divididos de acordo com a ordem em que aparecem no questionário aplicado.

\subsection{Perfil dos empreendedores e das startups}

São as seguintes as características dos participantes do estudo e de suas empresas:

- $86,4 \%$ dos gestores de startups de Minas Gerais participantes da pesquisa são do sexo masculino e 13,6\% são do sexo feminino;

- A maior parte dos empreendedores $(31,7 \%)$ possui idade entre 31 e 35 anos; 20\% deles têm de 26 a 30 anos; 20\% têm mais de 41 anos;

- A maior parte das startups de Minas Gerais participantes da pesquisa foi criada há mais de quatro anos (35\% delas); $26,7 \%$ foram criadas há dois anos;

- Quanto ao nível educacional, 33,3\% dos empreendedores possuem ensino superior; $28,3 \%$ possuem especialização; $21,7 \%$ possuem mestrado;

- Quanto à área de formação dos empreendedores, a maior parte deles advém dos campos de Ciências Exatas, Engenharia e Computação (45\%); 18,3\% são da Administração de Empresas, Economia e Contabilidade;

- A maior parte das startups(46,7\%) participantes possui até cinco colaboradores; $21,7 \%$ das empresas possuem de dez a 24 pessoas;

- Mais da metade das startups $(51,7 \%)$ tem o modelo de negócio B2B; $13,3 \%$ são Business to Consumer - B2C; $8,3 \%$ possuem SaaS; e $8,3 \%$ possuem outros modelos de negócio;

- Em termos de segmento de atuação, 18,3\% das startups de Minas Gerais participantes da pesquisa são do setor de varejo e e-commerce; $15 \%$ são da indústria; $13,3 \%$ são da área de educação; $11,7 \%$ são da área de saúde; e $31,7 \%$ são de outros segmentos. 


\subsection{O ambiente externo e a busca de informação}

O bloco de introdução do questionário teve como objetivo identificar a relevância dos setores do ambiente de negócios no dia a dia dos empreendedores, enquanto gestores e usuários de informação. Foram pesquisados os setores 'clientes', 'concorrentes', 'tecnologia', 'normas e regulamentações', 'situações econômicas' e 'situações socioculturais'. Para isso, foi utilizada uma escala de relevância de cinco graus: extremamente relevante, relevante, de alguma relevância, irrelevante e totalmente irrelevante. Para 95\% dos 60 empreendedores respondentes, os 'clientes' são extremamente relevantes; a 'tecnologia' foi destacada também como extremamente relevante para $53 \%$, ficando em segundo lugar; 'normas e regulamentações' apareceram em terceiro lugar como fatores extremamente relevantes para 25\%; em quarto lugar, são apontados os 'concorrentes' por 22\% dos empreendedores; na sequência, os gestores indicam como extremamente relevantes as 'situações econômicas' (17\%); e as 'situações socioculturais' (13\%) ficaram em último lugar.

Esses resultados confirmam a forte orientação dos gestores de startups e de suas empresas para os clientes, o que é mencionado por Blank; Dorf (2012) como estratégico e determinante para o sucesso. A questão tecnológica, muito vinculada à inovação, no caso das startups, é mencionada pelos empreendedores como segundo fator extremamente relevante, o que está de acordo também com as teorias de negócio que preconizam a gestão da inovação como estratégica para a perpetuação da organização. É o que orienta Ries (2011), que caracteriza a inovação como primordial para o sucesso das startups.

O segundo bloco do questionário teve como objetivo entender a contextualização da busca de informação pelos gestores de startups, por meio do seguinte enunciado: enquanto gestor, você busca informações para: 1) monitorar o mercado consumidor; 2) buscar novos conhecimentos para promover inovações na sua empresa; 3) fundamentar a tomada de decisões importantes. Foi adotada nesta questão a seguinte escala de frequência de busca de informação: sempre, quase sempre, às vezes, quase nunca e nunca. De acordo com as respostas, a maior parte dos empreendedores (63\%) sempre busca informação para adquirir novos conhecimentos para promover inovações; em segundo lugar, o objetivo de sempre buscar informações está ligado à tomada de decisão, apontada como fator mais relevante por $60 \%$ dos gestores; e, em terceiro lugar, foi escolhida a opção relacionada ao monitoramento de mercado, por $55 \%$ dos empreendedores.

\subsection{Relevância das fontes de informação}

As 30 fontes de informação foram apresentadas aos empreendedores entrevistados com a seguinte escala de relevância: extremamente relevante, relevante, de alguma relevância e irrelevante. Ainda foi oferecida a opção não utilizo a fonte. Conforme os dados 
apresentados na Tabela 1, para $83 \%$ dos respondentes, os clientes são considerados extremamente relevantes. Em segundo lugar, $75 \%$ dos empreendedores destacaram como fontes extremamente relevantes os sócios/empregados das startups. Em terceiro lugar, $52 \%$ dos respondentes apontaram como extremamente relevantes as bases de dados da própria empresa, o que sugere a autoconfiança dos gestores em informações concentradas em seus empreendimentos. Em quarto lugar, os buscadores web (sendo o Google o principal deles) são apontados como fontes de informação extremamente relevantes por $47 \%$ dos empreendedores. Na sequência, os empreendedores destacam como fontes de informação extremamente relevantes os parceiros e fornecedores $(37 \%)$, as redes sociais $(30 \%)$, outros empreendedores $(25 \%)$, concorrentes $(25 \%)$, leis, regulamentações e normas governamentais $(23 \%)$, artigos científicos, patentes, teses e dissertações $(20 \%)$, materiais ricos $(15 \%)$, relatórios financeiros e de mercado $(15 \%)$, blogs $(13 \%)$, congressos, feiras e eventos $(13 \%)$, material promocional $(13 \%)$, bancos, bolsa de valores e investidores (12\%).

Tabela 1: Grau de relevância das fontes de informações
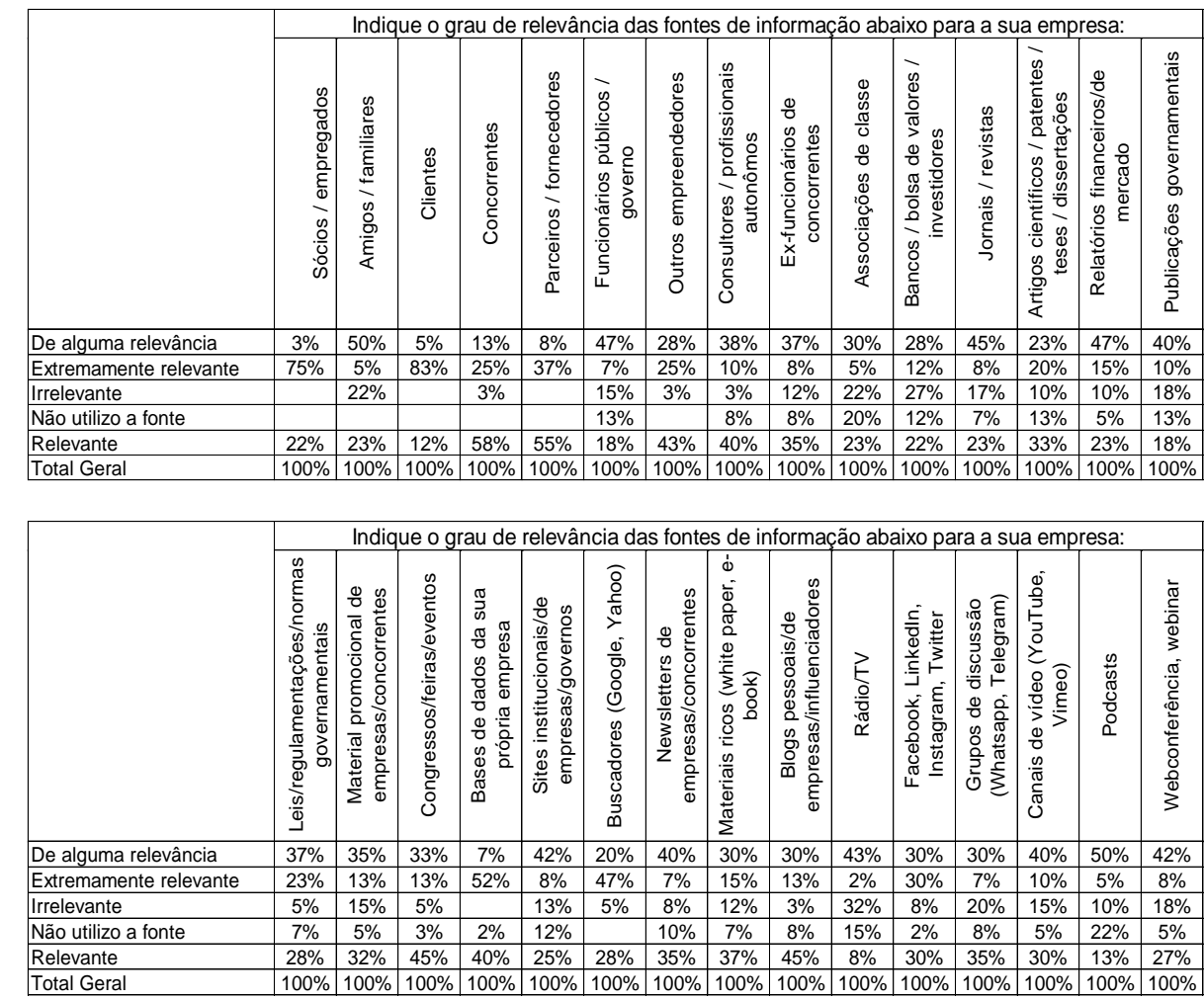

Fonte: Elaborado pelos autores, com base nos dados da pesquisa.

As redes sociais são apontadas pelos empreendedores de startups como fontes extremamente relevantes, à frente de outras tradicionais na literatura acadêmica, como empreendedores, concorrentes, leis, regulamentações e normas governamentais, artigos científicos, patentes, teses e dissertações. Nota-se também que fontes de informação tradicionais, como rádios e TVs, foram as mais citadas como irrelevantes 
(por 32\% dos empreendedores); na sequência, a maior irrelevância foi apontada para bancos/bolsa de valores/investidores (27\%). Da mesma forma, as associações de classe foram citadas como fontes não utilizadas por $20 \%$ dos empreendedores. Esses resultados sugerem uma descrença dos novos empreendedores em fontes de informação consideradas relevantes em outras pesquisas.

\subsection{Confiabilidade das fontes de informação}

A confiabilidade das fontes de informação foi analisada conforme a escala: extremamente confiável, confiável, razoavelmente confiável e nãoconfiável. Também foi dada a opção não utilizo a fonte. Como fonte de informação extremamente confiável, foram destacadas as bases de dados da própria empresa, por 55\% dos empreendedores. Em segundo lugar, $48 \%$ dos entrevistados elegeram os sócios/empregados. Na sequência, os respondentes apontaram as leis/regulamentações/normas governamentais (30\%) e artigos científicos/patentes/teses/dissertações (28\%). Esses resultados revelam a confiança dos empreendedores de startups nas bases de dados da própria organização, assim como nos seus sócios e empregados. O foco no próprio negócio, às vezes em detrimento de informações externas, pode ser traço do perfil de gestores de startups. De fato, para Perin (2015), muitos empreendedores possuem a "síndrome da genialidade", acompanhada de pensamentos como: 'minha ideia vai revolucionar o mundo', 'vai dar muito dinheiro' e 'é diferente de tudo que já se viu'.

Tabela 2: Grau de confiabilidade das fontes de informações

\begin{tabular}{|c|c|c|c|c|c|c|c|c|c|c|c|c|c|c|c|}
\hline & \multicolumn{15}{|c|}{ Indique o grau de confiabilidade das fontes de informação abaixo para a sua empresa: } \\
\hline & 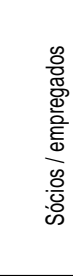 & 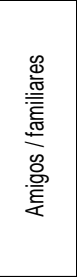 & 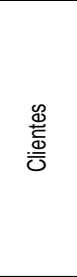 & 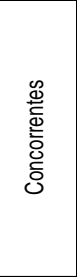 & 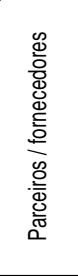 & 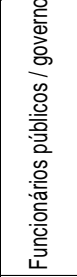 & 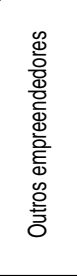 & 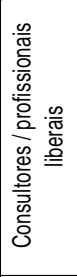 & 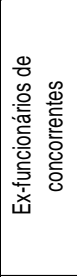 & 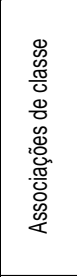 & 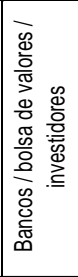 & 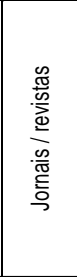 & 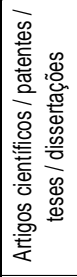 & 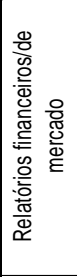 & 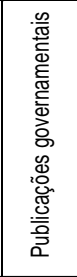 \\
\hline Confiável & $47 \%$ & $27 \%$ & $60 \%$ & $22 \%$ & $55 \%$ & $20 \%$ & $40 \%$ & $43 \%$ & $20 \%$ & $28 \%$ & $28 \%$ & $22 \%$ & $50 \%$ & $47 \%$ & $35 \%$ \\
\hline Extremamente confiável & $48 \%$ & $12 \%$ & $20 \%$ & $5 \%$ & $18 \%$ & $2 \%$ & $13 \%$ & $12 \%$ & $5 \%$ & $3 \%$ & $8 \%$ & $12 \%$ & $28 \%$ & $10 \%$ & $5 \%$ \\
\hline Não utilizo a fonte & & $8 \%$ & & $2 \%$ & & $12 \%$ & $2 \%$ & $3 \%$ & $5 \%$ & $15 \%$ & $15 \%$ & $5 \%$ & $8 \%$ & $5 \%$ & $12 \%$ \\
\hline Não-confiável & & $10 \%$ & $2 \%$ & $7 \%$ & $3 \%$ & $20 \%$ & $3 \%$ & $8 \%$ & $15 \%$ & $17 \%$ & $10 \%$ & $13 \%$ & $2 \%$ & $3 \%$ & $12 \%$ \\
\hline Razoavelmente confiável & $5 \%$ & $43 \%$ & $18 \%$ & $65 \%$ & $23 \%$ & $47 \%$ & $42 \%$ & $33 \%$ & $55 \%$ & $37 \%$ & $38 \%$ & $48 \%$ & $12 \%$ & $35 \%$ & $37 \%$ \\
\hline Total Geral & $100 \%$ & $100 \%$ & $100 \%$ & $100 \%$ & $100 \%$ & $100 \%$ & $100 \%$ & $100 \%$ & $100 \%$ & $100 \%$ & $100 \%$ & $100 \%$ & $100 \%$ & $100 \%$ & $100 \%$ \\
\hline
\end{tabular}

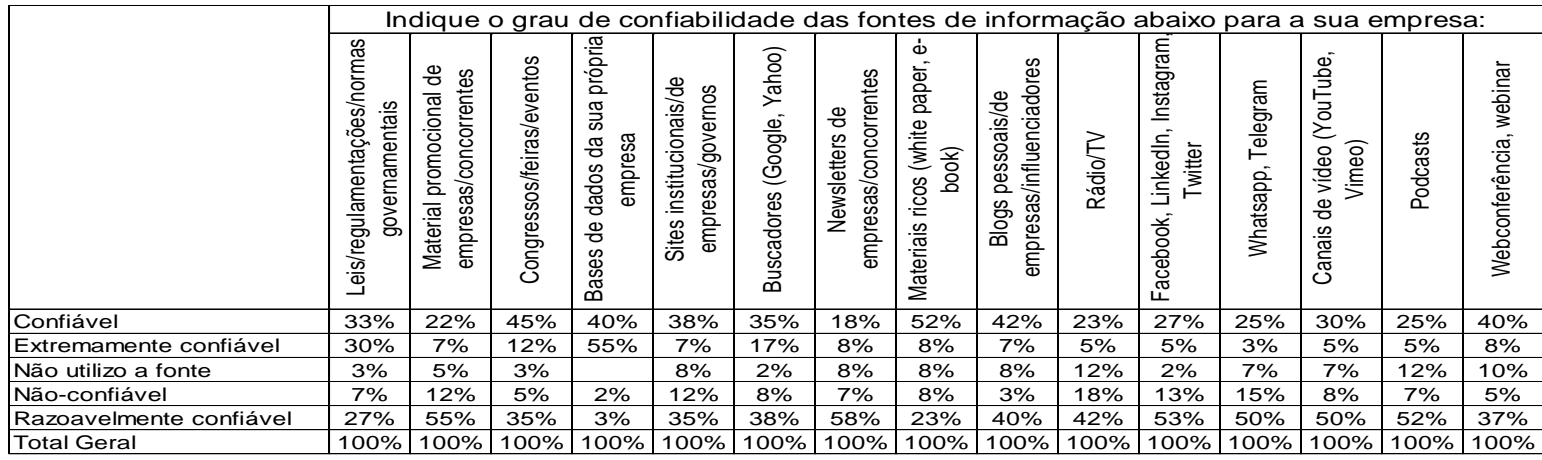

Fonte: Elaborado pelos autores, com base nos dados da pesquisa. 
Em relação às fontes de informação não-confiáveis, a pesquisa destaca em primeiro lugar a descrença nos funcionários públicos e no governo, item apontado por $20 \%$ dos empreendedores. Em segundo lugar, rádio e TV são as fontes não-confiáveis destacadas para $18 \%$ dos empreendedores. Na sequência, as fontes de informação não-confiáveis são: associações de classe (17\%), ex-funcionários de concorrentes (15\%), grupos de discussão, como WhatsApp e Telegram (15\%), jornais e revistas $(13 \%)$ e redes sociais $(13 \%)$.

\subsection{Análise qualitativa por três gestores dos resultados quantitativos}

Para analisar os resultados quantitativos da pesquisa, foram
convidados três gestores de instituições envolvidas com empreendedorismo e startups: um atua na gestão de um parque tecnológico de Minas Gerais (Gestor 1); outro está à frente de uma empresa de investimentos com atuação em Minas Gerais e em outros Estados (Gestor 2); o terceiro lidera um programa público de aceleração de startups de Minas Gerais (Gestor 3). As entrevistas foram individuais e feitas por telefone, com duração média de uma hora e meia cada.

Sobre o ambiente externo e a busca de informação, o Gestor 1 acredita que o destaque dado aos clientes é algo saudável, mas não é prioritário na decisão de empreender ou não. Na opinião dele, o resultado mostra a preocupação dos empreendedores em traduzir as demandas do cliente, de modo que elas orientem as soluções que a empresa irá desenvolver. Algumas frases confirmam esta visão: "O empreendedor define um foco e vai embora"; "Na prática, ele já tem uma trajetória definida, em termos de inovação e decisão, e tenta validar o que ele delimitou, com a busca de informação"; "O empreendedor tenta validar hipóteses de negócios quando está começando a empresa. Primeiro, ele resolve o que vai fazer, e depois vai olhar o cliente".

Segundo o Gestor 2, nos últimos dez anos, os empreendedores estão muito mais preparados, desenvolvendo o olhar no cliente, mas criar empresas com essa perspectiva ainda é um desafio para eles. "O empreendedor segue desenvolvendo conforme sua cabeça", disse. Conforme ele, na prática, observa-se o fazer de forma empírica, "torcendo pra dar certo". Para o Gestor 2, as startups não fazem uma boa pesquisa de mercado e as inovações são geradas muito mais a partir do feeling do empreendedor do que a partir de fundamentos do mercado e propostas de valor para o cliente. "A tomada de decisão é fruto de uma percepção do gestor", destacou.

Para o Gestor 1, a valorização dos ambientes internos das startups (sócios/empregados e bases de dados da empresa) enquanto fontes de informação demonstra a autoconfiança e a autorreferência dos empreendedores, que confiam nos dados que conseguem reunir e processar. Para ele, ao priorizar fontes internas, as startups perdem a oportunidade de expandir o negócio e desenvolver inovações disruptivas. 
"Não atribuir relevância às informações disponíveis de mercado é problemático e demonstra uma limitação. Não tem como promover inovações na empresa conversando só com clientes e empregados", disse.

Em relação à extrema relevância atribuída aos clientes e às fontes internas, o Gestor 2 acredita que as startups criam soluções "olhando para o próprio umbigo", em vez de olhar para fora. Na visão desse Gestor, faltam pesquisa e planejamento no ambiente dessas empresas. Ou seja, os empreendedores têm muita energia para executar, mas fazem pouco esforço no planejamento. "É uma deficiência grave", afirma.

A extrema relevância apontada pelos empreendedores à questão da tecnologia está de acordo com as preocupações percebidas pelo Gestor 3 . Este acredita que a tecnologia, no contexto do ambiente externo, tem relação com a "tecnologia do outro", que pode ser um concorrente ou mesmo um eventual parceiro no desenvolvimento de novas soluções. Os empreendedores de startups, na opinião do Gestor 3, estão preocupados com inovações que podem afetar ou "engolir" o seu negócio, fazendo com que ele desapareça.

O Gestor 1 apontou a valorização de ícones e personalidades do empreendedorismo, que ganham status no universo digital, o que pode ser representado pela importância atribuída aos blogs, fonte apontada com a mesma relevância que os congressos.

Quanto à confiabilidade das fontes de informação, o Gestor 1 interpretou, a partir dos resultados da pesquisa, que os empreendedores confiam em dados oficiais, mas não os caracterizam como relevantes. Da mesma forma, ao não confiarem em informações relacionadas à concorrência, os respondentes demonstram o despreparo de suas startups em desenvolverem relações efetivas de colaboração, as quais, às vezes, envolvem concorrentes. O Gestor 1 acredita que os apontamentos relacionados à falta de confiança refletem a imaturidade dos empreendedores no Brasil: não se confia no governo, nem no concorrente; apenas na própria empresa. Para ele, o gestor de startup acredita no que está fazendo e tem a crença de ser capaz de realizar.

O Gestor 2 ressalta a confiança em "outros empreendedores" percebida na pesquisa como realidade do ecossistema de Belo Horizonte. Para ele, "muitos empreendedores se aproximam de outros para desenvolverem estratégias conjuntas. As pessoas são hoje mais colaborativas. Pode-se dizer que houve uma evolução em termos de mentalidade empreendedora. Há o interesse nas parcerias", analisa.

O Gestor 3 confirma a prevalência de contatos informais nos ambientes de startups e destaca o uso frequente das ferramentas digitais, como WhatsApp, Live (do Facebook), Skype e Hangout, utilizadas para treinamentos e comunicação à distância, com clientes ou mentores. A informalidade tem a ver com o fato de as startups terem estruturas enxutas, e a documentação da informação, para o Gestor 3, deve ter o email como principal ferramenta. "A grande maioria das startups tem muitas ferramentas de gestão do trabalho e repositório de documentos, como Trello e Asana, além de ferramentas de gestão das opiniões do 
cliente, como Podium. Fazer a gestão de informação é algo importante", destacou.

Os resultados detalhados desta pesquisa podem ser consultados na dissertação de mestrado de Fonseca (2017), com informações complementares às apresentadas neste artigo.

\section{Conclusões}

Acredita-se que a amostra de empreendedores respondentes da pesquisa, ao abranger diversos segmentos de atuação, portes de empresa e tempo de criação, é representativa do conjunto das startups mineiras. A participação de três gestores, com experiência em projetos de incubação e aceleração de startups, na etapa qualitativa da pesquisa, ampliou as perspectivas de análise e a compreensão do movimento de busca e uso da informação por parte dos gestores de startups.

Percebeu-se, com a proposição de uma tipologia de 30 fontes de informação para este perfil de usuário e com os resultados alcançados, uma nova configuração em termos de relevância e confiabilidade de fontes de informação. Especificamente no universo de startups, o cliente e a tecnologia têm extrema relevância; notou-se também a preocupação primordial do gestor em gerar inovações e tomar decisões baseadas na busca de informação.

Os resultados da pesquisa evidenciaram a valorização do cliente enquanto fonte de informação prioritária, assim como a relevância e a confiabilidade das fontes internas das empresas, representadas por seus sócios/empregados e bases de dados próprias. Embora a autoconfiança seja uma característica importante para este tipo de empreendimento, a pesquisa registrou também, a partir da análise de especialistas que participaram da etapa qualitativa, o fato desses gestores estarem negligenciando as informações do ambiente externo, perdendo assim oportunidades de desenvolver parcerias e inovações.

Em termos de confiabilidade de fontes de informação, o trabalho apontou a descrença em relação a fontes tradicionais, consideradas confiáveis em outras pesquisas, como rádios, TVs, jornais e revistas. Ao mesmo tempo, as fontes de informação digitais ganharam maior relevância no dia a dia dos gestores, muito embora elas não sejam totalmente confiáveis. É o caso, por exemplo, das redes sociais.

Como contribuições para a Ciência da Informação, este estudo desenvolveu uma nova tipologia de fontes digitais, que poderá ser usada como referência em outras pesquisas do campo. Além disso, acredita-se que o trabalho contribuiu para ampliar os objetos de análise da área, considerando o tema empreendedorismo, tão relevante para a economia mundial. Como limitações da pesquisa, ressalta-se a escassez de artigos ou trabalhos acadêmicos relacionados a novas tipologias de fontes de informação digital; além disso, também não foram identificados, na literatura da área de Ciência da Informação, estudos relacionados ao tema startups e empreendedorismo. Dessa maneira, sugere-se o esforço dos 
pesquisadores em mapear e compreender o ecossistema de startups e de empreendedorismo de Minas Gerais e do Brasil, buscando identificar pontos de atenção e melhoria, sob diversos aspectos e estudos acadêmicos, para contribuir com a evolução desses negócios. 0 comportamento informacional de gestores permite um amplo universo de análises, assim como as maneiras pelas quais a informação é absorvida e processada nas organizações, gerando conhecimento e inovações.

\section{Referências}

ALVARENGA, Lídia. Representação do conhecimento na perspectiva da Ciência da Informação em tempo e espaços digitais. Encontros Bibli: Revista Eletrônica de Biblioteconomia e Ciência da Informação, Florianópolis, v.8, n.15, 2003. Disponível em: https://periodicos.ufsc.br/index.php/eb/article/view/15182924.2003v8n15p18/5233. Acesso em: 11 mar. 2018.

ASSOCIAÇÃO CATARINENSE DE TECNOLOGIA. Tech Report 2015: Panorama de Inovação e Tecnologia de Santa Catarina. Florianópolis, 2016.

ANASTÁCIO, Leila Aparecida; VIEIRA, Eliane Apolinário. Mapeamento de fontes de informação em ambiente web para ciência e tecnologia. Revista Digital de Biblioteconomia e Ciência da Informação, Campinas, v.11, n.1, p.83-92, jan./abr. 2013. Disponível em: https://periodicos.sbu.unicamp.br/ojs/index.php/rdbci/article/view/1653/p df. Acesso em: 11 mar. 2018.

BLANK, Steve; DORF, Bob. The startup owner's manual: the step-by-step guide for building a great company. California: K\&S Ranch Inc., 2012. v.1.

BRUM, Marco; BARBOSA, Ricardo Rodrigues. Comportamento de busca e uso da informação: um estudo com alunos participantes de empresas juniores. Perspectivas em Ciência da Informação, Belo Horizonte, v.14, n.2, p.52-75, 2009. Disponível em: http://portaldeperiodicos.eci.ufmg.br/index.php/pci/article/view/750/726. Acesso em: 11 mar. 2018.

BURKE, Peter. O preço do progresso. In: BURKE, Peter. Uma história social do conhecimento II: da enciclopédia à Wikipédia. Rio de Janeiro: Zahar, 2012. P.175-232.

CHOO, Chun Wei. A organização do conhecimento: como as organizações usam a informação para criar significado, construir conhecimento e tomar decisões. Tradução Eliana Rocha. São Paulo: Editora Senac, 2003.

DAVENPORT, Thomas H.; PRUSAK, Laurence. Conhecimento empresarial: como as empresas gerenciam o seu capital intelectual. Tradução Lenke Peres. Rio de Janeiro: Campus, 1998. P.1-28. 
DONMOYER, Robert. Quantitative research. In: LAVRAKAS, Paul J. (Ed.) Encyclopedia of survey research methods. Thousand Oaks, California: Sage, 2008. P.713-718.

DRUCKER, Peter. Sociedade Pós-Capitalista. 7 ed. São Paulo: Pioneira, 1998.

FONSECA, Flavia de Souza Magalhães. Uso de fontes de informação por gestores de startups. 2017. 92f. Dissertação (Mestrado em Ciência da Informação) - Escola de Ciência da Informação, Universidade Federal de Minas Gerais, Belo Horizonte.

GLOBAL ENTREPRENEURSHIP MONITOR. Empreendedorismo no Brasil: 2014. Curitiba: IBQP, 2014. 212p. Disponível em: http://observatorio.sebraema.com.br/empreendedorismo/pesquisa-gemempreendedores-do-brasil. Acesso em: 11 mar. 2018.

GLOBAL ENTREPRENEURSHIP MONITOR. Empreendedorismo no Brasil: 2015. Curitiba: IBQP, 2014. 178p. Disponível em: http://observatorio.sebraema.com.br/empreendedorismo/pesquisa-gemempreendedores-do-brasil. Acesso em: 11 mar. 2018.

GOMES, Clandia Maffini; KRUGLIANSKAS, Isak; SCHERER, Flávia Luciane. Gestão das fontes externas de informação: uma análise dos fatores que influenciam o desempenho inovador. Gest. Prod., São Carlos, v.18, n.4, p.897-910, 2011. Disponível em: http://www.scielo.br/pdf/gp/v18n4/a15v18n4.pdf. Acesso em: 11 mar. 2018.

HANK, Carolyn; JORDAN, Mary Wilkins; WILDEMUTH, Barbara M.. Survey research. In: WILDEMUTH, Barbara M. Applications of social research methods to questions in information and library science. Westport, Connecticut: Libraries Unlimited, 2009. P.256-269.

KOTHARI, Chakravanti Rajagopalachari. Processing and analysis of data. In: KOTHARI, Chakravanti Rajagopalachari. Research methodology: methods and techniques. New Delhi: New Age International Limited, 2004. P.122-151.

MALCZEWSKI, Marcel. Diário de um empreendedor. São Paulo: Évora, 2015.

MATTAR, Fauze. Pesquisa de marketing. São Paulo: Atlas, 1996.

PEREIRA, Frederico Cesar Mafra; BARBOSA, Ricardo Rodrigues. Uso de fontes de informação por consultores empresariais: um estudo junto ao mercado de consultoria de Belo Horizonte. Perspectivas em Ciência da Informação, Belo Horizonte, v.13, p.95-111, 2008.

PERIN, Bruno. A revolução das startups: o novo mundo do empreendedorismo de alto impacto. Rio de Janeiro, RJ: Alta Books, 2015. $172 p$. 
PIZZOL, Leandro Dal; TODESCO, José Leomar; TODESCO, Bernardo P. R.. Como a web de dados pode apoiar o processo de inteligência competitiva. Perspectivas em Gestão \& Conhecimento, João Pessoa, v. 6, n. especial, p. 87-102, jan. 2016.

RIES, Eric. The lean startup: how today's entrepreneurs use continuous innovation to create radically successful of businesses. New York: Crown Business, 2011.

RITCHIE, Jane. The applications of qualitative methods to social research. In: RITCHIE, Jane. Qualitative research practice: a guide for social science students and researchers. London: SAGE Publications, 2003. 352p.

RITZMANN, Bárbara Nascimento Barbosa. Redes sociais on-line como fontes de informação: considerações quanto ao modelo de uso da informação e ao modelo de criação de significado. 2012. $160 \mathrm{f}$. Dissertação (Mestrado Interdisciplinar em Ciência, Gestão e Tecnologia da Informação) - Universidade Federal do Paraná, Curitiba.

RODRIGUES, Charles; BLATTMANN, Úrsula. Gestão da informação e a importância do uso de fontes de informação para geração de conhecimento. Perspectivas em Ciência da Informação, Belo Horizonte, v.19, n.3, p.4-29, jul./set. 2014. Disponível em: http://dx.doi.org/10.1590/1981-5344/1515. Acesso em: 11 mar. 2018.

STEWART, Thomas A. Capital intelectual: a nova vantagem competitiva das empresas. Rio de Janeiro: Campus, 1998.

TAKEUCHI, Hideaki; NONAKA, Takashi. Gestão do conhecimento. Tradução Ana Thorell. Porto Alegre: Bookman, 2008. P.39-53.

TARAPANOFF, Kira (Org.) Inteligência, informação e conhecimento. Brasília: UNESCO/IBICT, 2006. 453p.

WILSON, Timothy D. Information behavior: an interdisciplinary perspective. Information Processing \& Management, Holanda, v.33, n.4, p.551-572, 1997. 